\title{
"Please mind the gap": successful use of ultrasound-assisted spinal anesthesia for urgent cesarean section in a patient with implanted spinal cord stimulation system for giant chest wall arteriovenous malformation - a case report
}

Bruno Antonio Zanfini* (D, Salvatore De Martino, Luciano Frassanito, Stefano Catarci, Francesco Vitale di Maio, Pietro Paolo Giuri, Gian Luigi Gonnella and Gaetano Draisci

\begin{abstract}
Background: The use of Spinal Cord Stimulation (SCS) system to treat medically refractory neuropathic pain is increasing. Severe neuropathic pain can be found in giant chest wall arteriovenous malformations (AVMs), exceedingly rare and debilitating abnormalities, rarely reported during pregnancy.

Case presentation: We present a report of a pregnant patient with implanted Spinal Cord Stimulation (SCS) system because of painful thoracic AVM scheduled for an urgent cesarean section in which we used lumbar ultrasound (US) to rule out the possibility to damage SCS electrodes and to find a safe site to perform spinal anesthesia.

Conclusions: The use of lumbar US to find a safe site for a lumbar puncture in presence of SCS system in a patient affected by painful thoracic AVM makes this case a particularly unique operative challenge and offers a new possible use of ultrasound to detect a safe space in patients with SCS implant.
\end{abstract}

Keywords: Spinal cord stimulation (SCS) system, Chest wall arteriovenous malformations, Cesarean section, Ultrasound

\section{Background}

The use of Spinal Cord Stimulation (SCS) system to treat medically refractory neuropathic pain is increasing [1]. Severe neuropathic pain can be found in giant chest wall arteriovenous malformations.

Arteriovenous malformations (AVMs) are rare abnormalities, associated with other congenital syndromes (Rendu-Osler-Weber Syndrome) or consequence of

\footnotetext{
* Correspondence: brunoantonio.zanfini@policlinicogemelli.it Fondazione Policlinico Universitario Agostino Gemelli IRCCS, Università Cattolica del Sacro Cuore, Scienze dell'Emergenza, Anestesiologiche e della Rianimazione, Largo A. Gemelli 8, 00168 Rome, Italy
}

trauma, infection, cancer. Congenital AVMs can be found usually in the central nervous system but can be reported in abdominal organs (liver and gastrointestinal tract), thoracic organs (lung and heart) and lower limb. Congenital chest wall AVMs are rare, with few case reports available in the literature [2-6], but extremely debilitating: if no treatment is performed thoracic AVMs can cause severe bleeding, cardiac failure associated with arteriovenous shunting and severe neuropathic thoracic pain.

We report a case of a 29 years old pregnant patient with a giant, congenital, painful AVM of the left chest

(c) The Author(s). 2020 Open Access This article is licensed under a Creative Commons Attribution 4.0 International License, which permits use, sharing, adaptation, distribution and reproduction in any medium or format, as long as you give appropriate credit to the original author(s) and the source, provide a link to the Creative Commons licence, and indicate if changes were made. The images or other third party material in this article are included in the article's Creative Commons licence, unless indicated otherwise in a credit line to the material. If material is not included in the article's Creative Commons licence and your intended use is not permitted by statutory regulation or exceeds the permitted use, you will need to obtain permission directly from the copyright holder. To view a copy of this licence, visit http://creativecommons.org/licenses/by/4.0/ The Creative Commons Public Domain Dedication waiver (http://creativecommons.org/publicdomain/zero/1.0/) applies to the data made available in this article, unless otherwise stated in a credit line to the data. 
wall, treated with implanted Spinal Cord Stimulation (SCS) system, admitted to our obstetric emergency room for an urgent cesarean section.

The presence of SCS system in pregnant patients with congenital AVM and the use of lumbar ultrasound (US) to perform a safe spinal anesthesia made this case a particularly unique operative challenge.

\section{Case presentation}

A 29 years old pregnant patient with singleton pregnancy at 38th gestational week (GW) was admitted to our obstetric emergency room for membrane rupture. She referred to be affected by a giant, congenital AVM of the left chest wall, extending from the third to the seventh thoracic interspace, involving the overlying thoracic muscles and the correspondent thoracic nerves, the rib cage, the parietal pleura, the transverse process of seventh thoracic vertebra and the scapular girdle, with severe neuropathic pain and reduced mobility in her left arm. She underwent to multiple embolizations to treat the lesion, with no or mild improvement of her pain despite she was taking $60 \mathrm{mg}$ Oral Morphine Equivalents (OME) per day and pregabalin $300 \mathrm{mg}$ twice daily. To treat her medically refractory neuropathic pain she was therefore referred for SCS system implant. A Model SC1200 Precision $^{\mathrm{m} w}$ Montage $^{\mathrm{m} w}$ Magnetic Resonance Imaging (Boston Scientific) was successfully implanted, with electrodes at thoracic level and Implantable Pulse Generator (IPG) in the left buttock. The procedure led to a dramatic improvement of the symptoms and withdrawal of opioids and antiepileptic drugs in 8 weeks. One year later she obtained a spontaneous pregnancy. During pregnancy her pain control improved, leading to SCS deactivation through the period. Despite the absence of stimulation she reported her neuropathic pain "go into remission". So she needed no other medications. Her pregnancy progressed normally until 38th GW. At admission just a pre-SCS implant Magnetic Resonance Imaging (MRI) was available (Fig. 1, axial view; Fig. 2, coronal view) thus making unpredictable the location of her SCS leads, extensions, and IPG. An urgent cesarean section was planned because of the membrane rupture and the risk of severe bleeding due to a possible AVM rupture in case of vaginal birth, due to the increasing of thoracic pressure during pushing (urgent CS type 3 according to NICE classification) [7]. To rule out a possible lesion to SCS system and to identify a safe lumbar interspace, a US assisted spinal anesthesia has been performed. No drugs have been administered before surgery. During anesthesiologic and surgical procedure standard hemodynamic monitoring has been provided for pregnant [Continuous Electrocardiographic monitoring (ECG), Pulse oximetry (SpO2), Non-invasive Blood Pressure (NIBP)]; fetal wellbeing has been registered by

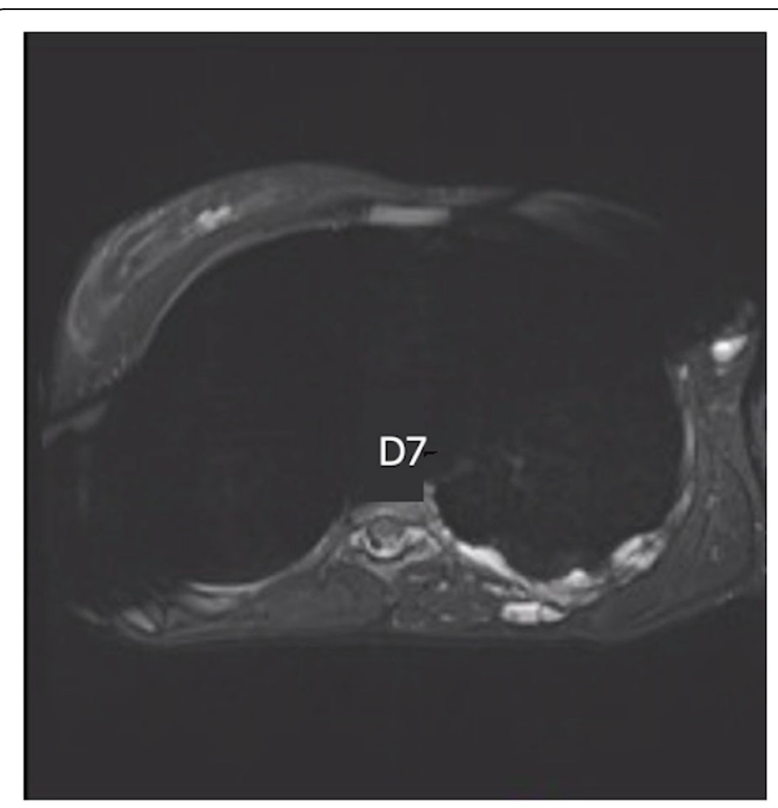

Fig. $1 \mathrm{MRI}$ axial view

cardiotocographic monitoring. Supplemental oxygen has been provided by Venturi mask. In sitting position, after skin disinfection with surgical solution (ChloraPrep", Carefusion, 244 LTD, UK) and using a broadband (5-8 $\mathrm{MHz}$ ) convex probe, a left US paramedian sagittal

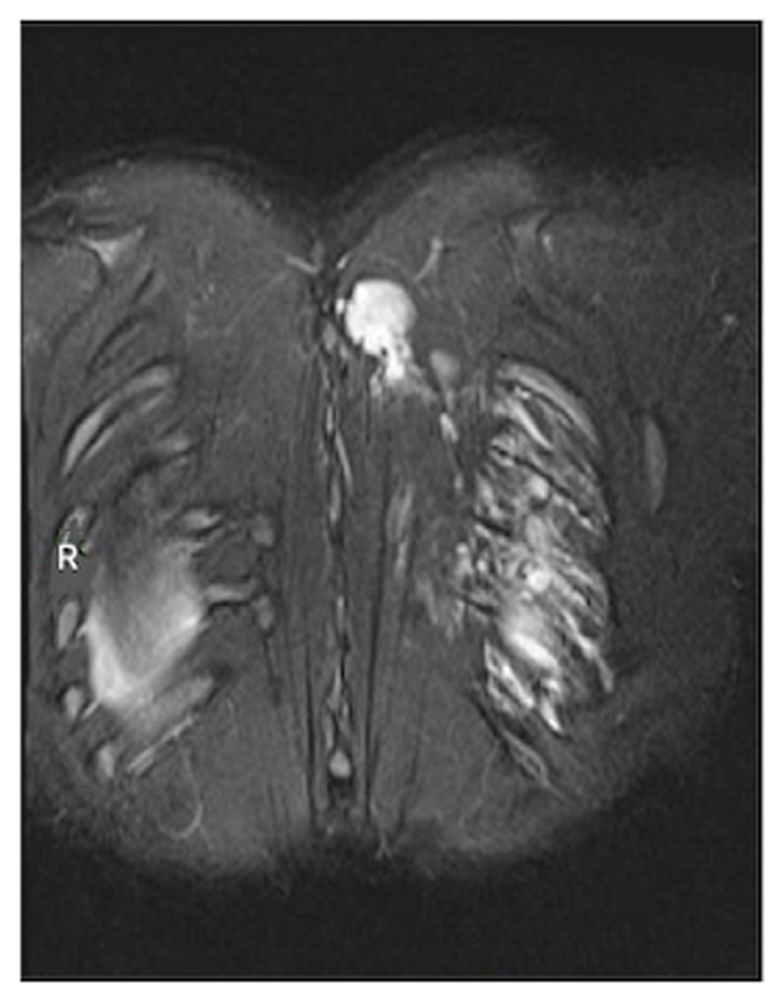

Fig. $2 \mathrm{MRI}$ coronal view 
oblique view has been obtained, starting at the sacrum and moving cephalad, to identify the L4-L5 lumbar interspaces (Fig. 3, paramedian sagittal oblique view). To identify the neuraxial midline, after rotating the probe $90^{\circ}$ into a transverse orientation, a transverse interlaminar view has been obtained (Fig. 4, transverse interlaminar view). No electrodes have been reported in that interspace. After local anesthesia with lidocaine 2\% (5 $\mathrm{mL}$ ) a 25-gauge Whitacre spinal needle has been used to perform a spinal anesthesia using hyperbaric bupivacaine $0.5 \% 10 \mathrm{mg}$ plus sufentanil $5 \mathrm{mcg}$ and morphine 100 mcg intrathecally administered. Surgical procedure started when T4 level has been reached. An uneventful cesarean section has been performed. A healthy 3395-g female baby was born (Apgar scores of 9-10 at both 1 and $5 \mathrm{~min}$ ). A postoperative thoracic X-Ray confirmed the right placement of thoracic electrodes but with entry point of SCS leads at L2-L3 interspace (Fig. 5, anteroposterior $\mathrm{X}$ ray; Fig. 6, lateral $\mathrm{X}$ ray). At postoperative day 3 patient has been discharged home.

\section{Discussion and conclusions}

Our case presents the successful use of lumbar US to detect a safe space for intrathecal injection in a patient with SCS implant because of thoracic AVM. Current data suggest that landmark identification using a preprocedure ultrasound (US) is a useful adjunct to neuraxial anesthesia [8-10] that facilitates technical performance in obstetric [11-13] and pediatric patients. In adult patients with difficult spinal anatomy $[14,15]$ a preprocedure US reduces the number of attempts [16] and the number of needle passes necessary for successful spinal anesthesia [16] and can predict technical difficulty $[14,17]$; notably, compared to fluoroscopy, sonography

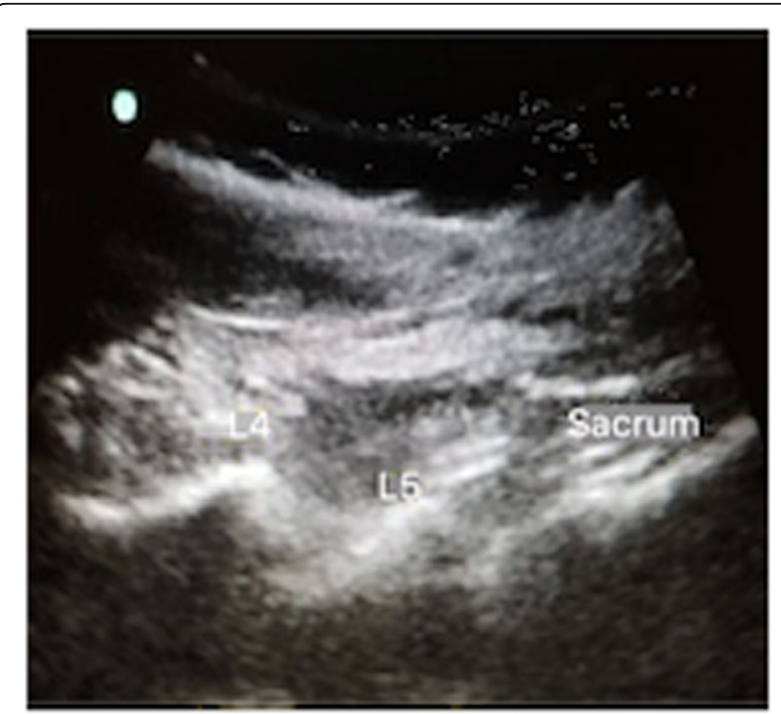

Fig. 3 Parasagittal oblique view of lumbar spine

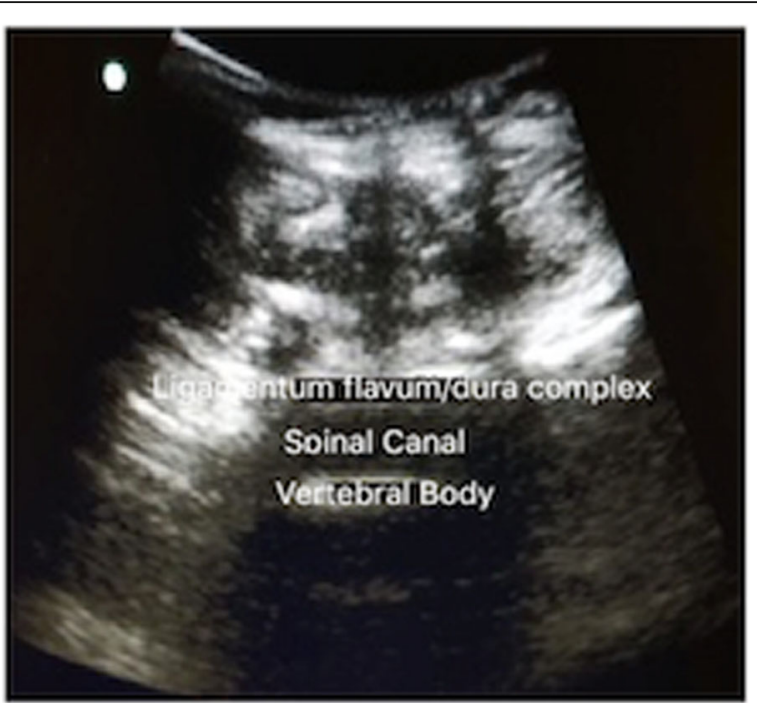

Fig. 4 Transverse interlaminar view at L4-L5 interspace

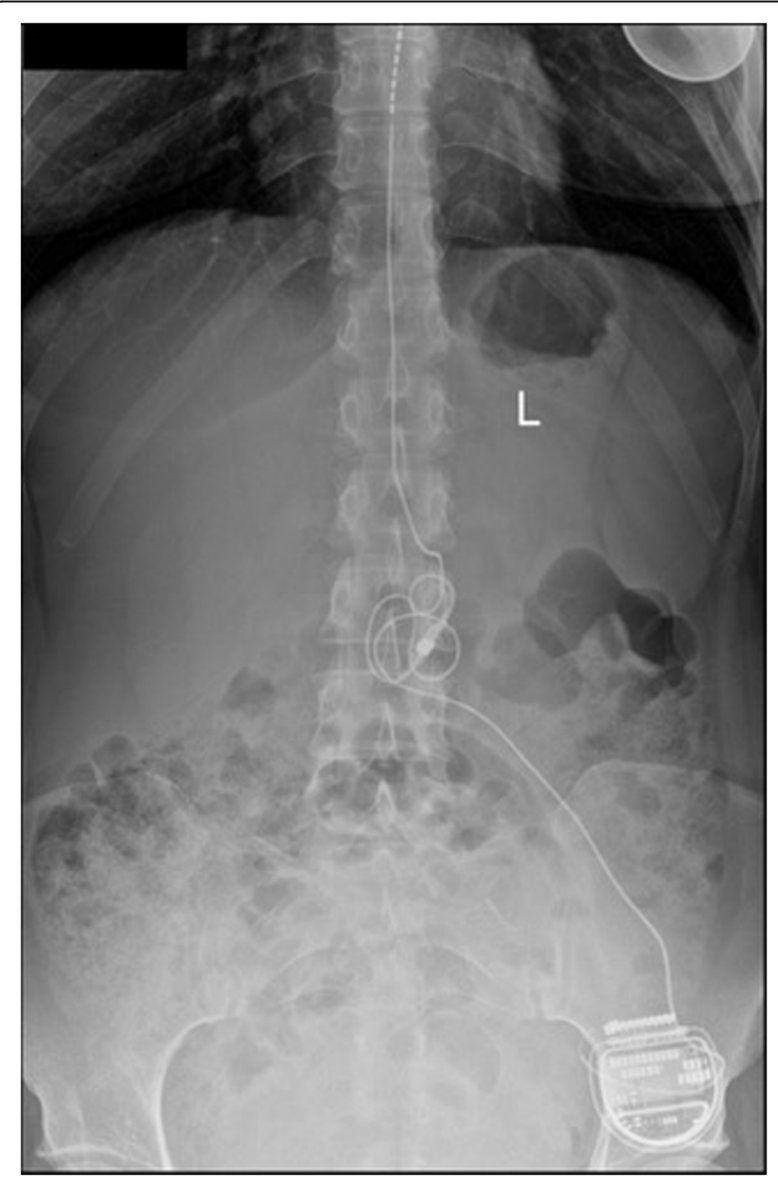

Fig. 5 Antero-posterior $X$ ray of lumbar and thoracic spine 


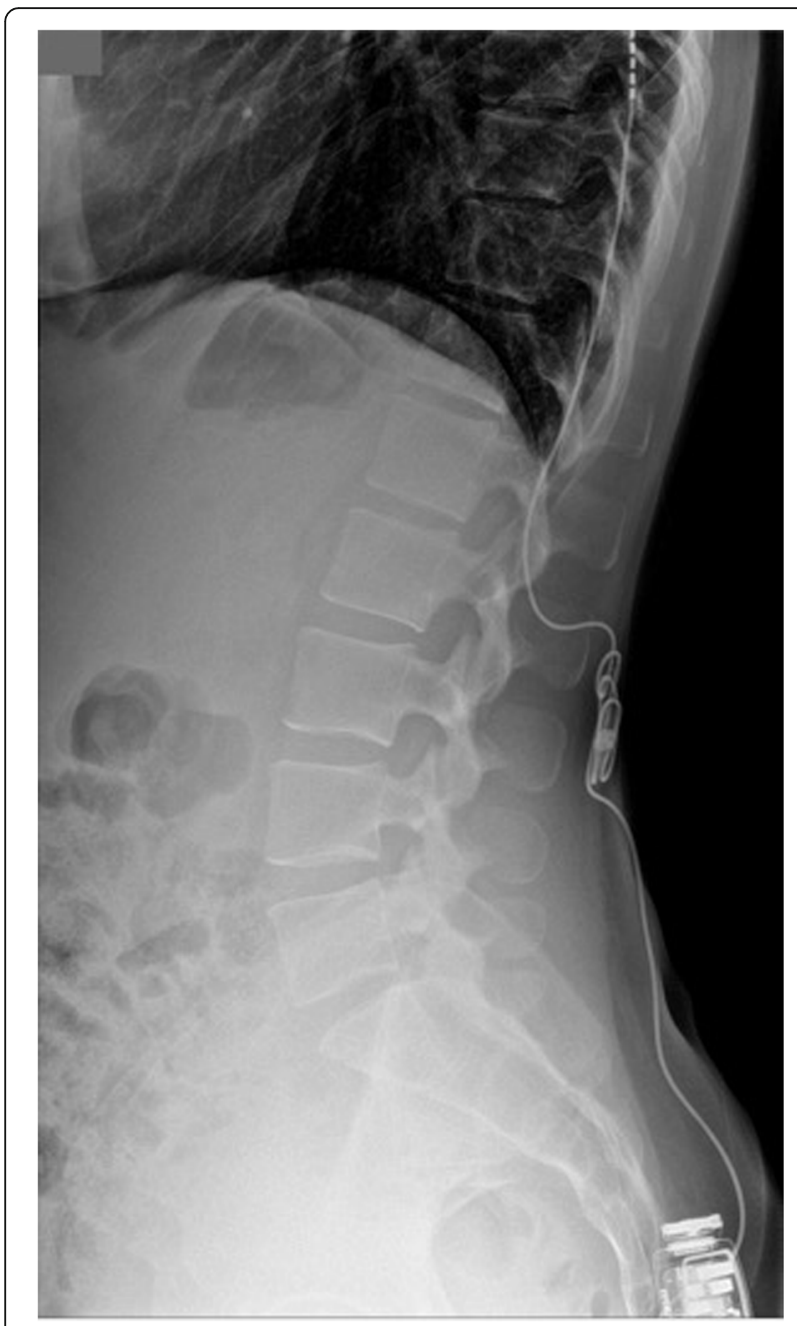

Fig. 6 Lateral $X$ ray of lumbar and thoracic spine

allows for the elimination of radiation exposure for physician and for patient, mostly when, as in our case during a urgent admission to obstetric emergency room, a X-ray scan to identify the location of SCS leads, extensions, and IPG cannot be performed. Even though the first description of a SCS implant for pain in pregnant patients occurred only in 1999 [18] the number of pregnant patients with SCS is increasing. Mostly of these pregnants are affected by Complex Regional Pain Syndrome (CPRS) or Failed Back surgery Syndrome (FBSS) [19-24] with a SCS system implanted before pregnancy occurred. Because leads migration is one of the most common complications occurring in from 2.1 to $27 \%$ out of 5000 patients undergoing SCS [25], we performed a lumbar ultrasound scan to identify a safe interspace where perform a spinal anesthesia. The safest choice of anesthesia for cesarean section in pregnant patients with a vascular malformation requires careful consideration. No data have been reported about thoracic AVMs to pregnancy; most of data can be derived from AVMs of Central Nervous System (CNS). Ong discussed the relative risks of different anesthetic choices for cesarean for a patient with a known cervical (C3) AVM that was stable throughout pregnancy [26]. Although general anesthesia can provide good hemodynamic stability, airway manipulation may lead to coughing and bucking with attendant increases in intrathoracic and venous pressures on waking from the anesthesia. This has potential to precipitate rupture of the cervical AVM. We supposed the same for thoracic AVMs and this is the reason why we choose a spinal anesthesia.

A critical decision for anesthetic management of patients with implanted SCS system for painful thoracic AVM scheduled for urgent cesarean section is the feasibility of providing a safe neuraxial anesthesia. Potential risks include damage to electrodes with the spinal or epidural needle, introducer, or catheter. Ultrasound examination may be useful to rule out these risks.

\section{Abbreviations \\ AVMs: Arteriovenous malformations; SCS: Spinal Cord Stimulation; \\ US: Ultrasound; OME: Oral Morphine Equivalents; IPG: Implantable Pulse Generator; ECG: Continuous Electrocardiographic monitoring; SpO2: Pulse oximetry; NIBP: Non-invasive Blood Pressure; MHz: MegaHertz; CPRS: Complex Regional Pain Syndrome; EMF: Electromagnetic force; CNS: Central Nervous System}

\section{Acknowledgements}

We thank Rosellina Russo MD for editorial assistance.

\section{Authors' contributions}

BAZ planned and conducted the case and drafted the manuscript. SDM conducted the case and revised the manuscript. LF acquired data and helped to write the manuscript. SC participated in the design of the case and helped in the draft of the manuscript. FVdiM studied the patient and planned anesthesiologic procedure. PPG acquired data and participated to planning of anesthesiologic procedure. GLG helped in the performing lumbar ultrasound. GD revised data, approved anesthesiologic procedure and revised the manuscript. All authors read and approved the final manuscript.

\section{Funding}

No funding has been obtained for this case report.

\section{Availability of data and materials}

All data generated or analyzed during this study are included in this published article.

\section{Ethics approval and consent to participate}

Ethic approval has not been requested for this case report.

\section{Consent for publication}

Enrolled patient gave her consent for publication in written format.

\section{Competing interests}

The authors declare that they have no competing interests.

Received: 14 January 2020 Accepted: 18 May 2020

Published online: 23 May 2020

\section{References}

1. Camporeze B, Simm RF, Estevão IA, Mathias-Junior LR, Aguiar PH, CarrondoCottin S. Spinal cord stimulation in the treatment of neuropathic pain: 
current perspectives of indications, cost-effectiveness, complications and results. J Health Sci. 2017;1:1-35. https://doi.org/10.17532/jhsci.2017.399.

2. Ulku R, Onat $\mathrm{S}$, Avci A, et al. Resection of intercostal hemangioma with involved chest wall and ribs in an 11-year- old girl. Texas Heart Inst J. 2010; 37(4):486-9 PMID:20844630.

3. Yilmaz S, Atinkaya C, Aktas A, et al. Giant arteriovenous malformation located on the chest wall-diagnosis and endovascular treatment: report of a case. Surg Today. 2010;40(12):1164-8. https://doi.org/10.1007/s00595-0094249-5.

4. Rivera PP, Kole MK, Pelz DM, et al. Congenital intercostal arteriovenous malformation. AJR Am J Roentgenol. 2006;187(5):W503-6. https://doi.org/10. 2214/AJR.05.0367.

5. Coulter TD, Maurer JR, Miller MT, et al. Chest wall arteriovenous fistula: an unusual complication after chest tube placement. Ann Thorac Surg. 1999; 67(3):849-50 PMID:10215249.

6. Urschel JD, Broad RW. Giant chest wall arteriovenous malformation with spinal cord compression. Postgrad Med J. 1995;71(834):252 PMID:7784298.

7. Caesarean section. NICE Clinical Guidelines, No. 132. National Collaborating Center for Women's and Children's Health (UK). London: RCOG Press; 2011. Accessed March 2020.

8. Sahin T, Balaban O, Sahin $L$, et al. A randomized controlled trial of preinsertion ultrasound guidance for spinal anaesthesia in pregnancy: outcomes among obese and lean parturients: ultrasound for spinal anesthesia in pregnancy. J Anesth. 2014;28:413-9. https://doi.org/10.1007/ s00540-013-1726-1.

9. Scapinelli R. Morphological and functional changes of the lumbar spinous processes in the elderly. Surg Radiol Anat. 1989;11:129-33 PMID:2763004.

10. Angle P, Tang SL, Thompson D, et al. Expectant management of postdural puncture headache increases hospital length of stay and emergency room visits. Can J Anaesth. 2005;52:397-402 PMID: 15814755.

11. Vallejo MC, Phelps AL, Singh S, et al. Ultrasound decreases the failed labor epidural rate in resident trainees. Int J Obstet Anesth. 2010;19:373-8. https:// doi.org/10.1016/j.ijoa.2010.04.002.

12. Grau T, Leipold RW, Conradi R, et al. Efficacy of ultrasound imaging in obstetric epidural anesthesia. J Clin Anesth. 2002;14:169-75 PMID:12031746.

13. Grau T, Leipold RW, Fatehi S, et al. Real time ultrasonic observation of combined spinal-epidural anaesthesia. Eur J Anaesthesiol. 2004;21(1):25-31 PMID:14768920.

14. Chin KJ, Perlas A, Chan V, et al. Ultrasound imaging facilitates spinal anesthesia in adults with difficult surface anatomic landmarks. Anesthesiology. 2011;115:94-10. https://doi.org/10.1097/ALN. Ob013e31821a8ad4.

15. Willschke $H$, Bosenberg $A$, Marhofer $P$, et al. Epidural catheter placement in neonates: Sonoanatomy and feasibility of ultrasonographic guidance in term and preterm neonates. Reg Anesth Pain Med. 2007;32:34-40 PMID: 17449890.

16. Kallidaikurichi Srinivasan $\mathrm{K}$, lohom G, Loughnane F, et al. Conventional landmark-guided midline versus Preprocedure ultrasound-guided paramedian techniques in spinal anesthesia. Anesth Analg. 2015;121:108996. https://doi.org/10.1213/ANE.0000000000000911

17. Chin KJ, Ramlogan R, Arzola C, et al. The utility of ultrasound imaging in predicting ease of performance of spinal anesthesia in an orthopedic patient population. Reg Anesth Pain Med. 2013;38:34-8. https://doi.org/10 1097/AAP.0b013e3182734927.

18. Segal R. Spinal cord stimulation, conception, pregnancy, and labor: case study in a complex regional pain syndrome patient. Neuromodulation. 1999;2:41-5. https://doi.org/10.1046/j.1525-1403.1999.00041.x.

19. Sommerfield $D, H u P, O$ O'Keeffe $D$, et al. Caesarean section in a parturient with a spinal cord stimulator. Int J Obstet Anesth. 2010;19:114-7. https://doi. org/10.1016/j.ijoa.2009.08.006.

20. Bernardini DJ, Pratt SD, Takoudes TC, et al. Spinal cord stimulation and the pregnant patient-specific considerations for management: a case series and review of the literature. Neuromodulation. 2010;13:270-4. https://doi.org/10. 1111/j.1525-1403.2010.00288.x.

21. Domínguez Suárez E, Camblor Suárez E, Vázquez Del Valle S, et al. Epidural analgesia in a woman with spinal neurostimulation for complex regional pain syndrome type 1. A clinical case and literature review. Rev Esp Anestesiol Reanim. 2012;59(9):515-6. https://doi.org/10.1016/..redar.2012.05.041.

22. Fedoroff IC, Blackwell E, Malysh L, et al. Spinal cord stimulation in pregnancy: a literature review. Neuromodulation. 2012;15:537-41. https:// doi.org/10.1111/j.1525-1403.2012.00448.
23. Ito S, Sugiura T, Azami T, et al. Spinal cord stimulation for a woman with complex regional pain syndrome who wished to get pregnant. J Anesth. 2013;27:124-7. https://doi.org/10.1007/s00540-012-1462-y.

24. Das B, McCrory C. Spinal cord stimulation in pregnancy with failed back surgery syndrome. Ir Med J. 2014;107(4):117-8 PMID: 24834587.

25. Eldabe S, Buchser E, Duarte RV. Complications of spinal cord stimulation and peripheral nerve stimulation techniques: a review of the literature. Pain Med. 2016;17:325-36 PMID: 26814260.

26. Ong BY, Littleford J, Segstro R, et al. Spinal anaesthesia for Caesarean section in a patient with cervical arteriovenous malformation. Can J Anaesth. 1996:43(10):1052-8 PMID: 8896858.

\section{Publisher's Note}

Springer Nature remains neutral with regard to jurisdictional claims in published maps and institutional affiliations.
Ready to submit your research? Choose BMC and benefit from:

- fast, convenient online submission

- thorough peer review by experienced researchers in your field

- rapid publication on acceptance

- support for research data, including large and complex data types

- gold Open Access which fosters wider collaboration and increased citations

- maximum visibility for your research: over $100 \mathrm{M}$ website views per year

At BMC, research is always in progress.

Learn more biomedcentral.com/submissions 